\title{
A sustained increase of input current distortion in active input current shapers to eliminate electrolytic capacitor for designing ac to dc HB-LED drivers for retrofit lamps applications
}

\author{
D. G. Lamar, M. Arias and J. Sebastian \\ Universidad de Oviedo. Grupo de Sistemas Electrónicos \\ de Alimentación (SEA) \\ Edificio Departamental n ${ }^{\circ}$ 3. Campus Universitario de \\ Viesques. \\ 33204 Gijón. SPAIN \\ gonzalezdiego@uniovi.es
}

\author{
A. Fernandez ${ }^{1}$ and J. A. Villarejo ${ }^{2}$ \\ ${ }^{1}$ ESA - European Space Agency \\ Noordwijk - THE NETHERLANDS \\ arturo.fernandez@esa.int \\ ${ }^{2}$ Universidad P de Cartagena \\ Departamento de Tecnologia Electronica \\ Cartagena, SPAIN \\ jose.villarejo@upct.es
}

\begin{abstract}
Nowadays, the solid-sate lighting technology evolution has changed traditional solutions in lighting. HighBrightness Light-Emitting Diodes (HB-LEDs) have become very attractive light sources due to their excellent characteristics: high efficiency, high life-time and low maintenance. It is evident that HB-LED drivers must be durable and efficient to achieve these advantages. Moreover, for replacing incandescent bulbs, the ac-dc HB-LED driver must be low cost and comply with international regulations (i.e. injection of low frequency harmonics into the mains). Traditionally, authors have focused its efforts on increasing efficiency. All these solutions obviate the elimination of traditional electrolytic capacitor of ac to dc converters, highlighting that this is the price to pay for a very low-cost solution. This paper presents a new proposal to design a simple and low-cost ac to de HB-LED driver for retrofit lamps without electrolytic capacitor. The proposed solution comes from a very well-known technique used in the past: Active Input Current Shapers (AICS), but in this case without electrolytic capacitor. If the electrolytic capacitor of an AICS is removed, then low frequency ripple arises in its intermediate dc bus, increasing the distortion of the line input which already has appreciable distortion. However, the increase of distortion is very slight. Also, the low frequency ripple is not transferred to the output due to the high output dynamic response of AICS, avoiding flickering. This paper presents a theoretical analysis that guarantees a trade of between compliance with international regulations and the use of other capacitor technologies different from the electrolytic one. Finally, a $24 \mathrm{~W}$ experimental prototype has been built and tested in order to validate the theoretical results presented in this digest.
\end{abstract}

Keywords-Ac to dc power conversion, harmonic distortion, LEDs, lighting, power factor, switched mode power supplies.

\section{INTRODUCTION}

It is known that High-Brightness Light-Emitting Diodes (HB-LEDs) are a fast emergent technology, considered as the true alternative to many mature technologies (i.e. incandescent bulbs, compact fluorescent lamps, etc.) due to its high efficiency, low maintenance and durability. To perform these advantages HB-LED drivers must be both durable and efficient.

Since HB-LEDs are diodes, the default method for driving them is controlling the dc forward current trough this semiconductor device. If the primary energy source is the ac line, then some type of ac to dc converter must be placed between the line and the HB-LEDs. Also, it is known that the low-frequency harmonic content of the line current must comply with specific regulations (IEC 61000-3-2 [3-5] and ENERGY STAR $\AA$ program [6]). Traditionally, these regulations establish a very strict harmonic content for lighting (e.g. IEC 61000-3-2, Class C), so that only sinusoidal line waveforms is able to comply with the aforementioned regulations. Therefore, the only practical method to comply with these regulations is to use active high Power Factor (PF) converters. These converters are known as Power Factor Correctors (PFCs), which are expensive and complex solutions. However, for power levels lower than 25 $\mathrm{W}$ the compliance with IEC 61000-3-2 regulation becomes more relaxed due to the fact that luminaries must comply with this regulation in Class D [6]. Hence, new solutions can arise.

A possible application for substituting incandescent bulbs lamps is to use two strings of around 10 HB-LEDs of $1 \mathrm{~W}$ in parallel connected to the output of an ac to dc driver to produce the same luminance flux as the one produced by a $100 \mathrm{~W}$ incandescent bulb. These configurations supply output voltages around of $20 \mathrm{~V}$ and power levels lower than $24 \mathrm{~W}$. The most extended solution adopted is to use a flyback converter operating in Discontinuous Conduction Mode (DCM) with switching frequencies below $100 \mathrm{kHz}$ in order to obtain efficiencies around $82 \%$. Traditionally, authors have focused their efforts on increasing the efficiency of the ac-to-dc driver in spite of increasing its cost and complexity. Some examples are solutions based on an asymmetrical half bridge flyback converter [7], two

This work was supported by the Spanish Ministry of Education and Science under Project MINECO-13-DPI2013-47176- C2-2-R, by Government of the Principality of Asturias under the Project FC-15-GRUPIN14-143 and by European Regional Development Fund (ERDF) grants. 
stage resonant buck converter [8] or tapped-inductor buck converter [9-10]. However, all these proposals exhibit a main drawback: the use of an electrolytic capacitor to reduce the low frequency ripple of the output current.

This paper presents a low-cost ac to dc HB-LED driver conceived from a well-known concept: the Active Input Current Shapers (AICS). The proposal of this solution comes from the latest regulations modifications for low power lighting equipment (i.e. IEC 61000-3-2, Class D) which are now more relaxed than previous ones (i.e. IEC 61000-3-2, Class C), and therefore, a sinusoidal input current is not needed. In AISCs, if the electrolytic capacitor that stabilize intermediate bus is substituted by other technology, then some low frequency ripple arises in the intermediate bus, increasing the distortion of the line current. However, this added distortion is slight in comparison to traditional distortion of AICS, validating the proposed idea without electrolytic capacitor. Moreover, due to its fast dynamic response, the low frequency ripple is not transferred to the output. Finally, an ac to dc HB-LED driver for retrofit lamps applications without electrolytic capacitor is achieved.

\section{REVEWING ACTIVE INTUT CURRENT SHAPER (AICS)}

\section{A. Basic concepts about AISC}

The concept of the AICS is very well known in the design of ac to dc Switching Mode Power Supplies (SMPS), [13-17]. This solution is based on conventional dc to dc converters with a slight modification: an additional output, obtained from the converter transformer (Fig. 1a), is connected between the diode bridge and the bulk capacitor $\left(\mathrm{C}_{\mathrm{B}}\right)$.

This output is called "delayed output" in [11] and it was proposed into the context of two fully regulate outputs in de to dc converters [12]. It seems similar to a conventional forward output. However, an extra inductor $\left(\mathrm{L}_{\mathrm{D}}\right)$ is placed between one terminal of the secondary side transformer and the diode $\mathrm{D}_{1}$ (Fig. 1a). With this extra inductor and with $\mathrm{L}$ working in Continuous Conduction Mode (CCM, i.e. $\left.\mathrm{L}>>\mathrm{L}_{\mathrm{D}}\right)$, the Thévenin equivalent circuit of the "delayed output" becomes a voltage source $\left(\mathrm{V}_{\mathrm{S}}\right.$, see Fig. 1b) a loss-free resistor ( $\mathrm{R}_{\mathrm{LF}}$, see Fig. 1b). This "delayed output" recycles some amount of energy redirecting it to the input in order to shape line input current. By properly choosing the values of these two elements (i.e. $V_{S}$ and $R_{L}$ ), the AISC can achieve both high efficiency and limited low-frequency harmonic content of input current.

The current in a half cycle of input voltage can be easily deduced from the AICS behavior. The input rectifier start to conduct when input voltage (i.e. $\mathrm{V}_{\mathrm{g}}(\mathrm{t})=\mathrm{V}_{\mathrm{gp}} \cdot\left|\sin \left(\omega_{\mathrm{L}} \mathrm{t}\right)\right|$ ) reaches $\left(\mathrm{V}_{\mathrm{S}}-\mathrm{V}_{\mathrm{C}}\right)$. Thus, the expression of the rectified input current can be expressed as:

$$
i_{g d c}(t)=\frac{V_{g p} \cdot\left|\sin \left(\omega_{L} t\right)\right|-V_{C}+V_{S}}{R_{L F}},
$$

where $\mathrm{V}_{\mathrm{C}}$ is the voltage of intermediate bus, $\omega_{\mathrm{L}}$ and $\mathrm{V}_{\mathrm{gp}}$ are the angular frequency and the peak value of input voltage respectively. It should be noted that this expression is only valid for the interval $\left[\left(\pi-\phi_{C}\right) / 2,\left(\pi+\phi_{C}\right) / 2\right]$, being $\phi_{C}$ the conduction angle (see Fig. 1). By equaling (1) to zero, the expression of the conduction angle can be easily calculated:

$$
\phi_{C}=2 \cos ^{-1}\left(\frac{V_{C}-V_{S}}{V_{g p}}\right) .
$$

Therefore, the line input current is defined by (1) into the $\left[\left(\pi-\phi_{\mathrm{C}}\right) / 2,\left(\pi+\phi_{\mathrm{C}}\right) / 2\right]$ interval and by zero outside of this interval of positive semi-cycle of the line input voltage. Also, in the same way for the negative semi-cycle of the line input voltage (see Fig. 1). Moreover, it is important to say that the higher $\phi_{\mathrm{C}}$ the greater amount of energy recycled to the input, and therefore, the lower efficiency.

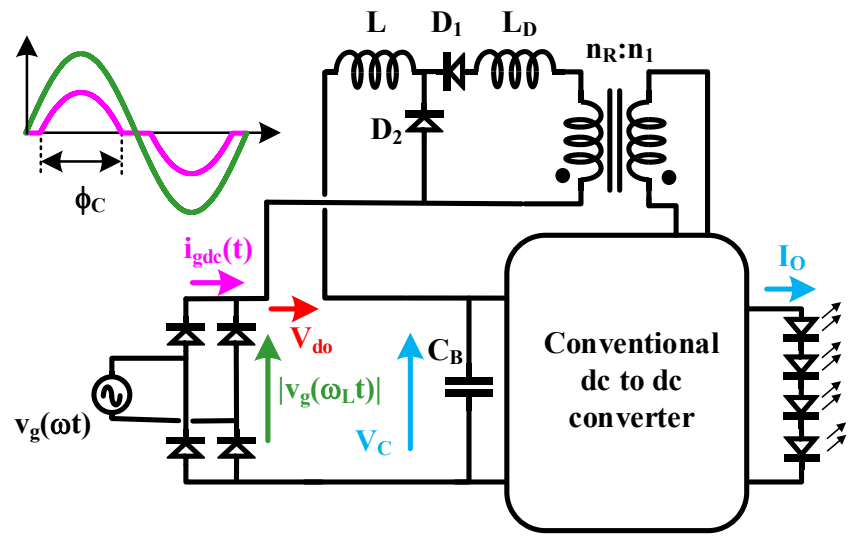

(a)

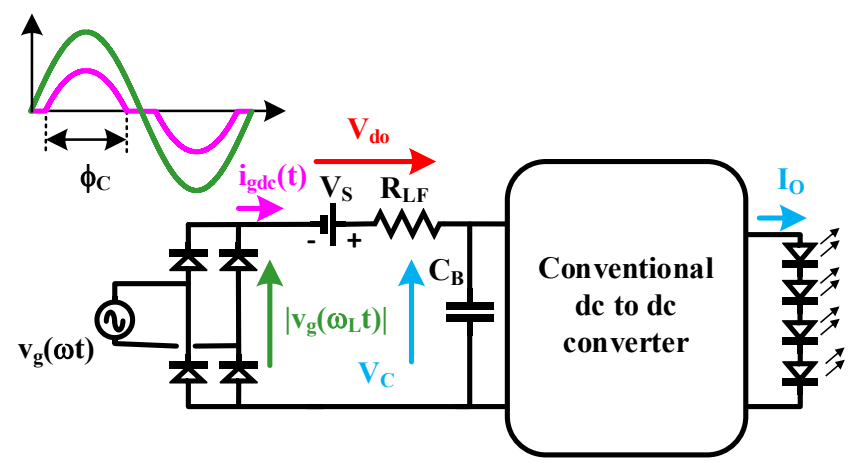

(b)

Fig. 1. a) AISC solution. b) Equivalent circuit of AISC.

From the expression of the input voltage, (1) and (2), the average input power will be:

$$
\begin{gathered}
P_{g}=\frac{1}{\pi} \int_{\left(\phi_{C}-\pi\right) / 2}^{\left(\phi_{C}+\pi\right) / 2}\left[i_{g d c}(t) \cdot V_{g p} \cdot\left|\sin \left(\omega_{L} t\right)\right|\right] d t= \\
=\quad \frac{V_{g p}{ }^{2}}{2 \pi R_{L F}}\left(\phi_{C}-\sin \left(\phi_{C}\right)\right) .
\end{gathered}
$$

The rectified input current can be rewritten as a function of the average input power, conduction angle and peak value of the input voltage by using (1), (2) and (3):

$$
i_{g d c}(t)=\frac{2 \pi P_{g}}{V_{g p}}\left(\frac{\left|\sin \left(\omega_{L} t\right)\right|-\cos \left(\frac{\phi_{C}}{2}\right)}{\phi_{C}-\sin \left(\phi_{C}\right)}\right) .
$$

Also, from (4), it is easy to obtain the minimum $\phi_{\mathrm{C}}$ value which complies with international regulations for a given input voltage (i.e. the minimum $\phi_{C}$ which introduce higher efficiency). Table I shows these minimum values (i.e. $\phi_{C \text { min }}$ ) which are the 
same for the american and european mains supply. Some of these values have been previously calculated in $[15,17]$. As you can see in Table I, the more restrictive regulation the higher value of $\phi_{\mathrm{Cmin}}$. At this point, the input current of the AICS can be represented. Figure 2 shows the normalized input current for several optimized designs that both comply international regulations at nominal input voltage and maximize efficiency. All Fig. 2 designs have been performed by following [15, 17] design procedure.

TABLE I. MINIMUN VALUE OF $\phi_{\mathrm{C}}$ WHICH COMPLIES WITH INTERNATIONAL REGULATIONS

\begin{tabular}{cc}
\cline { 2 - 2 } & $\phi_{\text {Cmin }}\left({ }^{\circ}\right)$ \\
\hline EN 61000-3-2 Class C regulations & 140.49 \\
\hline EN 61000-3-2 Class D regulations & 63.12 \\
\hline ENERGY STAR ${ }^{\circledR}$ residential applications & 103.87 \\
\hline ENERGY STAR ${ }^{\circledR}$ for commercial applications & 55.59 \\
\hline
\end{tabular}

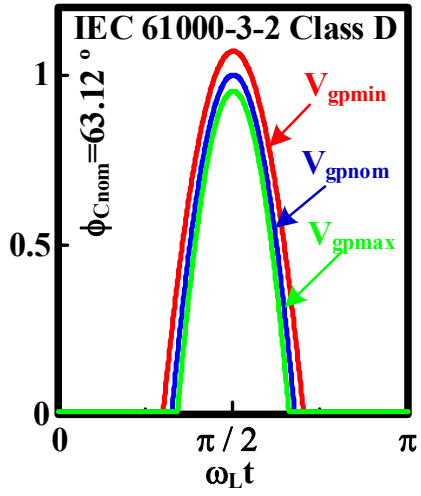

(a)

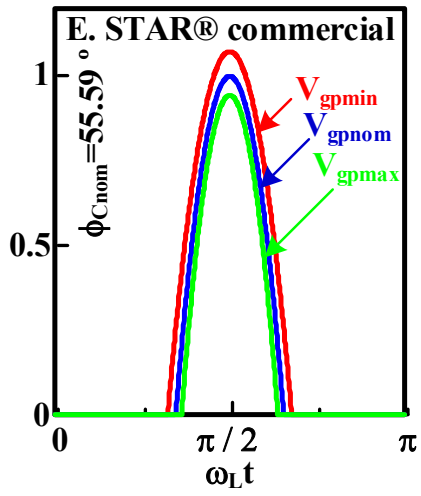

(a)

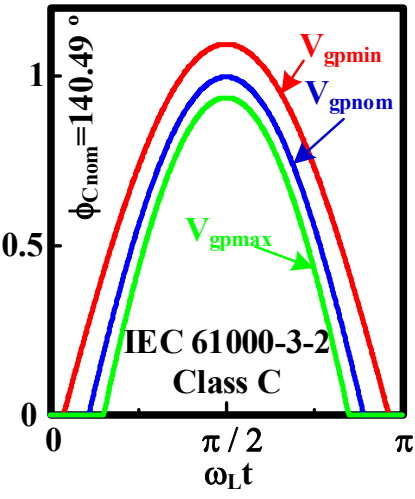

(b)

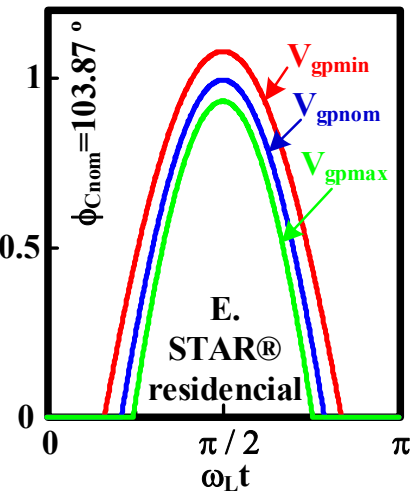

(b)
Fig. 2. Normalized input current for different optimized designs at different peak values of $\mathrm{v}_{\mathrm{g}}(\mathrm{t})$ : a) Class $\mathrm{D}$ european design. b) Class $\mathrm{C}$ european design. c) ENERGY STAR $®$ american desing for comercial applications. d) ENERGY STAR $®$ american desing for residential applications.

\section{B. Inplementation of the voltage source and the LFR with the forward "delayed output"}

From the analysis of the forward "delayed output" presented in [11], $\mathrm{V}_{\mathrm{S}}$ and $\mathrm{R}_{\mathrm{LF}}$ can be calculated. Figure 3 shows the equivalent circuit of the "delayed output". As you can see, it is a forward output, but with an additional inductor $L_{D}$ in series with the rectifier diode $\mathrm{D}_{1}$. Due to the action of this inductor, there is a delay between the turn-off of $\mathrm{D}_{2}$ in comparison to traditional forward output. In fact $\mathrm{D}_{2}$ stops conducting later because $L_{D}$ must be charged until $i_{L}(t)$ (i.e. $i_{L D}(t)$ reaches $i_{L}(t)$ ) by the action of the voltage reflected to the secondary side of the transformer of the forward "delayed output" (see Fig.3b).

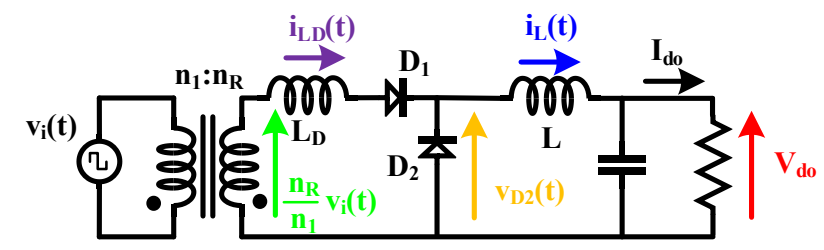

(a)

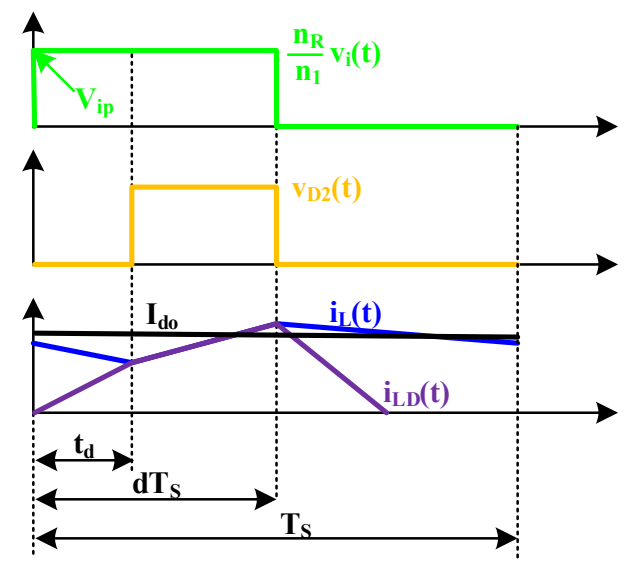

(b)

Fig. 3. a) "Delayed ouput". b) Main waveforms.

From Fig. $3 b$ the delay time can be deduced applying Faraday's law to the "delayed output":

$$
t_{d}=\frac{i_{L}\left(t=t_{d}\right)}{\frac{n_{R}}{n_{1}} \cdot v_{i}(t)},
$$

where $v_{i}(t) n_{R} / n_{1}$ is the voltage reflected in the secondary side of the forward "delayed output", $\mathrm{n}_{\mathrm{R}} / \mathrm{n}_{1}$ being the turns ratio of the transformer.

The effective duty cycle at the input of the output LC filter can be deduced from Fig. 3b:

$$
d^{\prime}=d-t_{d} \cdot f_{s}
$$

where $d$ is the duty cycle and $f_{S}=1 / T_{S}$ the switching frequency, $\mathrm{T}_{\mathrm{S}}$ being the switching period.

Assuming that there is no ripple through inductor $\mathrm{L}$ because the forward "delayed output" operates in CCM (i.e. $L>>L_{D}$ ), the output voltage of the "delayed output" is:

$$
V_{d o}=\frac{n_{R}}{n_{1}} \cdot V_{i p} \cdot d-L_{D} \cdot f_{s} \cdot I_{o d},
$$

where $V_{\text {ip }}$ is the peak value of $\mathrm{v}_{\mathrm{i}}(\mathrm{t})$ and $\mathrm{I}_{\mathrm{od}}$ is the output current of the "delayed output". From Fig. 1, we can deduce that the forward "delayed output" becomes a real source voltage. Therefore equation (6) can be rewritten as follows: 


$$
V_{d o}=V_{S}-R_{L F} \cdot I_{o d}
$$

where:

$$
\begin{gathered}
V_{S}=\frac{n_{R}}{n_{1}} \cdot V_{i p} \cdot d, \\
R_{L F}=L_{D} \cdot f_{s} .
\end{gathered}
$$

It should be noted that no energy is dissipated in the $\mathrm{R}_{\mathrm{LF}}$ if all components are ideal. Finally, it is important to say that $\mathrm{L}_{D}$ energy is transferred to the primary side of the transformer, in this case to the equivalent voltage source $\mathrm{v}_{\mathrm{i}}(\mathrm{t})$.

\section{Using a flyback converter to design the AISC}

Figure 4 shows the implementation of an AISC in a flyback converter (it will be equal on a member of the flyback's family of $\mathrm{dc}$ to dc converters, that is, SEPIC, Cuk and Zeta). First, Fig. 4a defines the basic implementation. Second, two modifications of this implementation are shown in Fig. 4b and Fig. 4c, where the transformer becomes an autotransformer. Finally, Fig. $4 \mathrm{~d}$ shows a particularization on Fig. 4c solution. This is an easy implementation of proposed idea, ideal for low-cost solutions. This implementation only introduce two extra inductors and two extra diodes in comparison to traditional flyback topology. The price to pay is the loss of a degree of freedom in the design of the AISC, because the autotransformer disappears (i.e. $n_{R}=n_{1}$ ).

By using a flyback topology in order to implement the AICS, the input voltage of the dc to dc converter becomes $\mathrm{V}_{\mathrm{C}}$. Taking into account CCM operation, the following equation can be written:

$$
V_{O}=\frac{n_{2}}{n_{1}} \cdot V_{C} \cdot \frac{d}{1-d},
$$

where $\mathrm{n}_{2}$ is the number of turns of the secondary side of the transformer. Moreover equation (8) becomes:

$$
V_{S}=\frac{n_{R}}{n_{1}} \cdot V_{C} \cdot d
$$

As (11) shows, $V_{S}$ depend on $V_{C}$, the duty cycle and the turn ratio of the "delayed output". In fact a properly choice of $n_{R} / n_{1}$ allow us to freely set $V_{S}$. Also $V_{C}$ and $V_{S}$ are related by the fact that the output voltage of the AISC must be kept constant by the action of the feedback loop. A new equation must be deduced by using (2), (10) and (11):

$$
V_{C}-\frac{n_{R}}{n_{1}} \cdot V_{C} \cdot \frac{V_{O}}{\frac{n_{2}}{n_{1}} \cdot V_{C}+V_{O}}=V_{g p} \cdot \cos \left(\frac{\phi_{C}}{2}\right) .
$$

From (3) and (12), the evolution of $V_{C}$ as a function of the design parameters (i.e. the conduction angle for nominal conditions and full load, $\phi_{C \text { nom, }}$, and the duty cycle for minimum peak value of the input voltage, $\mathrm{d}_{\max }$ ) can be calculated. $\mathrm{V}_{\mathrm{C}}$ could be represented versus input power for different $V_{g p}$ values. Figure 5 shows the voltage on the intermediate bus for different optimized designs following $[15,17]$ design procedure. (the same as Fig. 2 designs). [15,17] optimized design procedures is focused on minimizing $\mathrm{VC}$ value and the amount of recycled energy, keeping compliance with international regulations at nominal input voltage and full load. By an adequate choice of $\mathrm{n}_{\mathrm{R}} / \mathrm{n}_{1}$ the voltage drop across the series connection of $\mathrm{V}_{\mathrm{S}}$ and $\mathrm{R}_{\mathrm{LF}}$ could be zero at minimum input voltage $\mathrm{V}_{\mathrm{gpmin}}$ and full load $\left(\mathrm{P}_{\mathrm{gmax}}\right)$. In this conditions $\mathrm{V}_{\mathrm{C}}\left(\mathrm{i} . \mathrm{e} \mathrm{V}_{\mathrm{Cmin}}\right)$ becomes equal to $\mathrm{V}_{\text {gpmin }}$.
Although $\mathrm{V}_{\mathrm{C}}$ is minimized, it is not maintained constant for different operation conditions (i.e. $\mathrm{P}_{\mathrm{g}}$ and $\mathrm{V}_{\mathrm{gp}}$ variations),

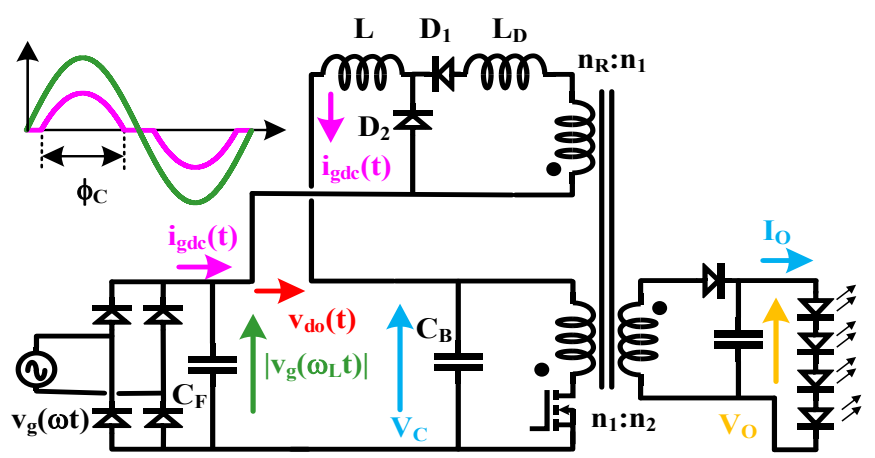

(a)

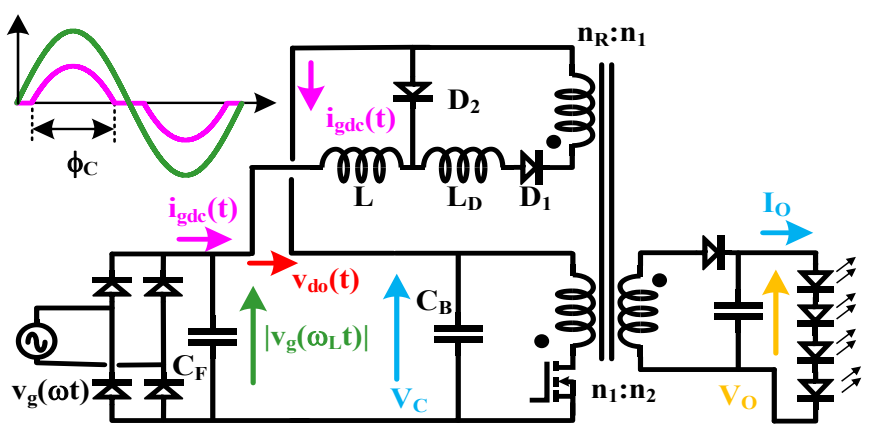

(b)

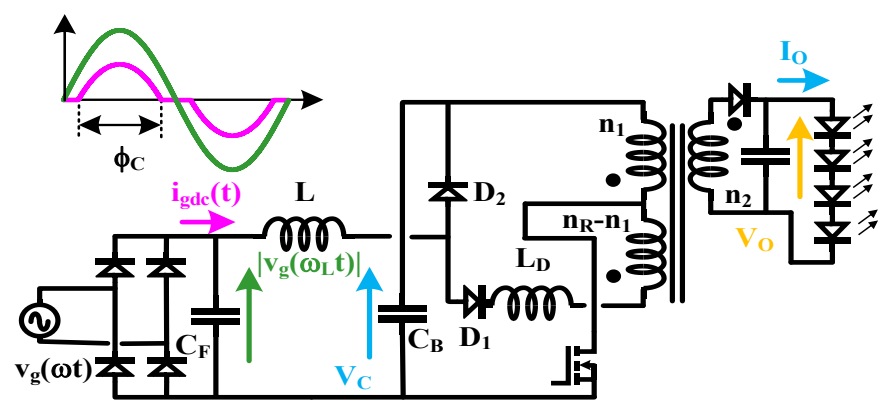

(c)

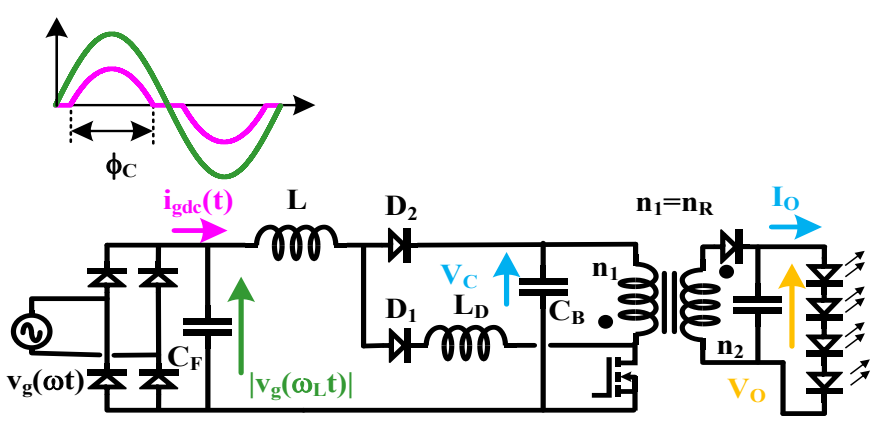

(d)

Fig. 4. Implementation of AISC based on flyback converter. a) Basic scene. b) After moving $\mathrm{L}, \mathrm{L}_{\mathrm{D}}, \mathrm{D}_{1}$ and $\mathrm{D}_{2}$. c) Using an extra tap instead of "delayed output". d) Using no extra tap $\left(\mathrm{n}_{1}=\mathrm{n}_{\mathrm{R}}\right)$.

at least if the flyback converter is operating at constant switching frequency, as Fig. 5 shows. This is the price to pay due to the simplicity of this solution in comparison to two-stage solution, 
where the voltage across the intermediate bus is controlled. Finally, it is important to say that in Fig. $4 \mathrm{~d}$ structure, $\mathrm{V}_{\mathrm{C}}$ limiting cannot be achieved due to the fact that $n_{R} / n_{1}$ is set a priori.

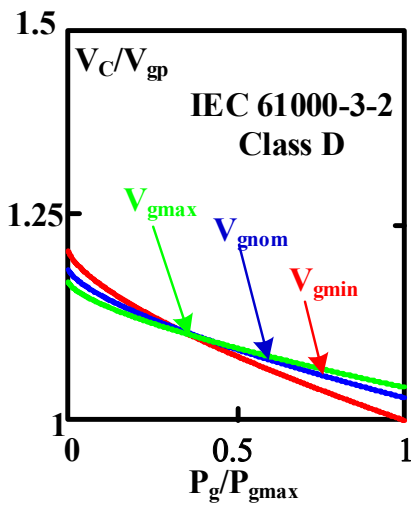

(a)

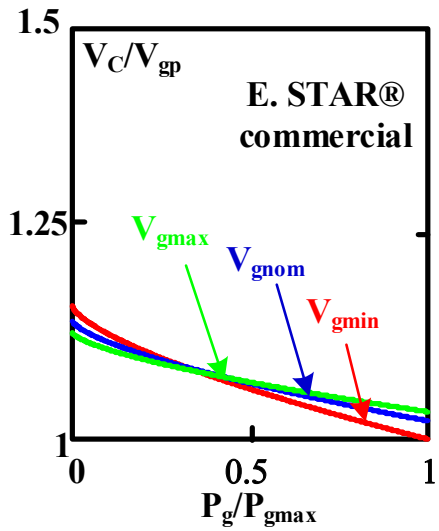

(c)

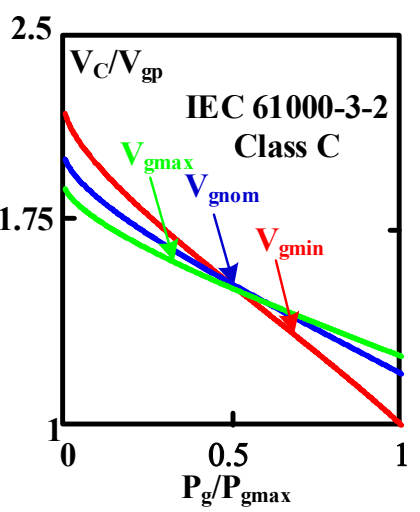

(c)

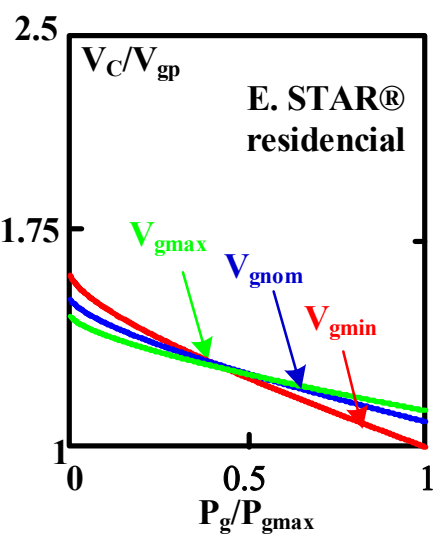

(d)
Fig. 5. Normalized voltage of the intermediate bus versus normalized power at different peak values of the input voltage for differerent optimized designs. a) Class D european design. b) Class $\mathrm{C}$ european design. c) ENERGY STAR ${ }^{\circledR}$ american desing for comercial applications. d) ENERGY STAR ${ }^{\circledR}$ american desing for residential applications.

\section{EXPERIMENTAL RESULTS: INCREASING LOW FREQUENCY VOLTAGE RIPPLE OF AISC IN THE INTERMEDIATE BUS TO ELIMINATE ELECTROLITHYC CAPACITOR}

A prototype of the proposed ac-dc HB-LED driver based on an AISC was design to widely comply with regulations (i.e. IEC 61000-3-2, Class D and ENERGY STAR ${ }^{\circledR}$ program requirements for commercial applications), built and tested. A design has been performed following $[15,17]$ for next specifications: $\phi_{\text {Cnom }}=70^{\circ}, \mathrm{P}_{\mathrm{g}}=24 \mathrm{~W}, \mathrm{~V}_{\mathrm{O}}=19 \mathrm{~V}, \mathrm{f}_{\mathrm{S}}=110 \mathrm{kHz}$, american design (i.e. $90 \sqrt{2}<\mathrm{V}_{\mathrm{gp}}<130 \sqrt{2}$ and $60 \mathrm{~Hz}$ ), CCM operation of the "delayed output" (i.e. $\mathrm{L}=1,8 \mathrm{mH}$ ) and $\mathrm{d}_{\max }=0.6$. The circuit has been performed according to the scheme given in Fig. 6a, where $\mathrm{R}_{\mathrm{LF}}=43.45$ (i.e. $\mathrm{L}_{\mathrm{D}}=0.39 \mathrm{mH}$ ), $\mathrm{n}_{\mathrm{S}}=\mathrm{n}_{1}$ and $\mathrm{n}_{2} / \mathrm{n}_{1}=0.1$. The prototype was controlled using a commercial IC as is shown in Fig. 6b (UC2825 by Texas Instruments). Finally, the converter output is connected to a matrix of two strings in parallel of 6 HB-LEDs each one. Table II summarize all main components.

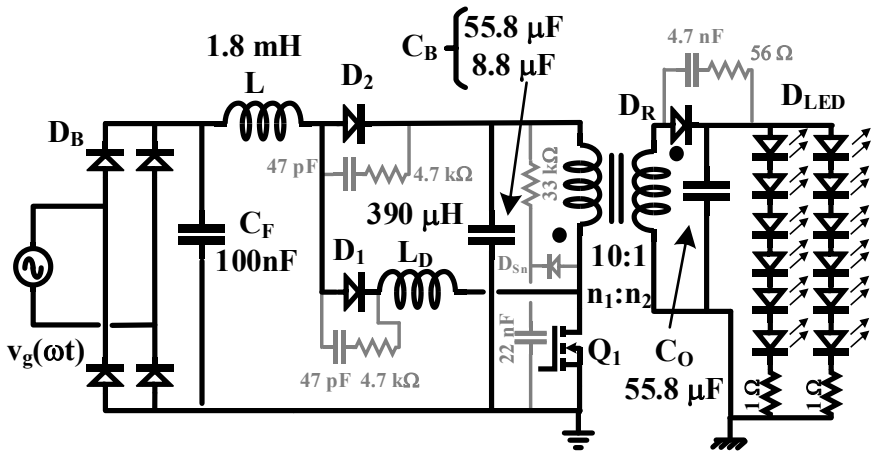

(a)

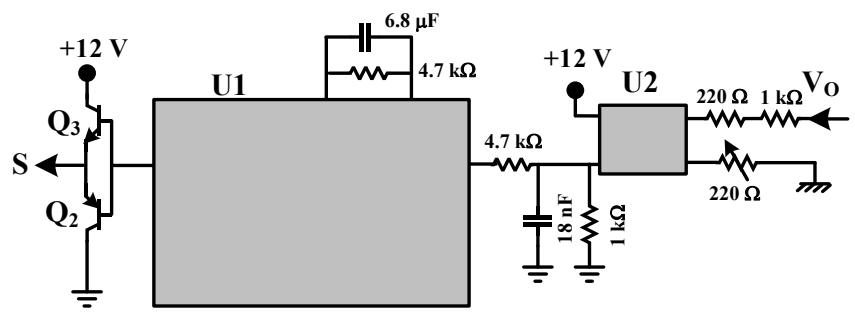

(b)

Fig. 6. Experimental prototype based on flyback converter. a) Power stage. b) Control stage.

TABLE II. COMPONENTS OF HE EXPERIMENTAL PROTOTYPE

\begin{tabular}{cc}
\hline \multicolumn{1}{c}{ Fig. 6 reference } & Value \\
\hline$D_{1}$ & BYP08P140 \\
\hline$D_{2}$ & HFADBTB \\
\hline$D_{\mathrm{B}}$ & 3KBP04M \\
\hline$D_{\mathrm{R}}$ & 8TQ100 \\
\hline$D_{\mathrm{Sn}}$ & MUR4100 \\
\hline$D_{\mathrm{LED}}$ & LXK2PW14T00 (Luxeon) \\
\hline $\mathrm{Q}_{1}$ & BDPF8N80C \\
\hline $\mathrm{Q}_{2}$ and $\mathrm{Q}_{3}$ & UC3825 \\
\hline $\mathrm{U}_{1}$ & MCT2 \\
\hline $\mathrm{U}_{2}$ &
\end{tabular}

A. AISC without low frequency ripple in the intermediate bus $\left(C_{B}=55.8 \mu F\right)$

The prototype was tested until both the prototype temperature and the HB-LEDs temperature stabilized at the aforementioned specifications. The final operating temperature was reached after $45 \mathrm{~min}$ of operation. Figure 7 shows the line input current, voltage in the intermediate bus, input voltage and output voltage of the AISC. As expected, the experimental results of $i_{g}(t)$ match with the theoretical ones. Also, the voltage of intermediate bus is around $200 \mathrm{~V}$, being the expected one. In this implementation $\mathrm{V}_{\mathrm{C}}$ cannot be controlled, however, this is the price to pay for using an implementation as simple as the one of proposed (i.e. $\mathrm{n}_{1}=\mathrm{n}_{\mathrm{R}}$ ).

\section{B. AISC with low frequency ripple in the intermediate bus $(C B=8.8 \mu F)$}

In this second test, the electrolytic capacitor of the intermediate bus $\left(\mathrm{C}_{\mathrm{B}}=47 \mu \mathrm{F}\right)$ has been removed and only the ceramic capacitor remains $\left(\mathrm{C}_{\mathrm{B}}=4 \times 2.2 \mu \mathrm{F}\right)$. As a consequence of this, some low frequency ripple arises at the voltage of the intermediate bus (see $v_{C}(t)$ in Fig. 8) which increase the traditional distortion of the AICS line input current. This added 
distortion is slight in comparison to traditional distortion of AICS (see $i_{g}(t)$ in Fig. 8). Moreover, this slightly increase of the input current distortion can be explicitly checked in comparison to the first test (Fig. 9). As you can see, compliance with IEC 61000-3-2 Class D international regulations is achieved too. Table III shows also compliance with ENERGY STAR $®$ program requirements for commercial applications and the slight increase of THD and slight decrease of PF.

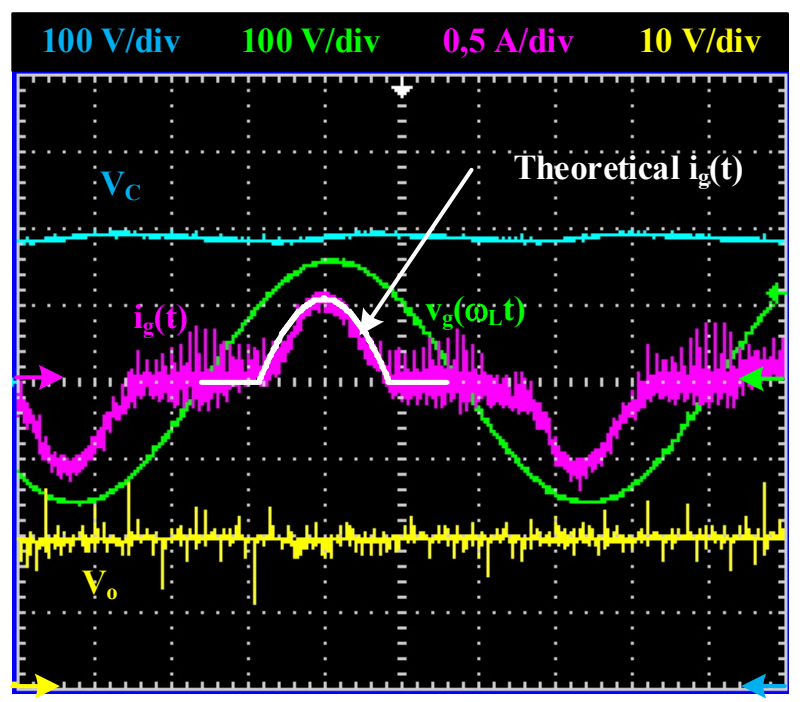

Fig. 7. Line input current $\left(\mathrm{i}_{\mathrm{g}}(\mathrm{t})\right)$, voltage of the intermediate bus $\left(\mathrm{V}_{\mathrm{C}}\right)$, line input voltage $\left(\mathrm{v}_{\mathrm{g}}(\mathrm{t})\right)$ and output voltage $\left(\mathrm{V}_{\mathrm{O}}\right)$ of the AISC without low frequency ripple in the intermediate bus.

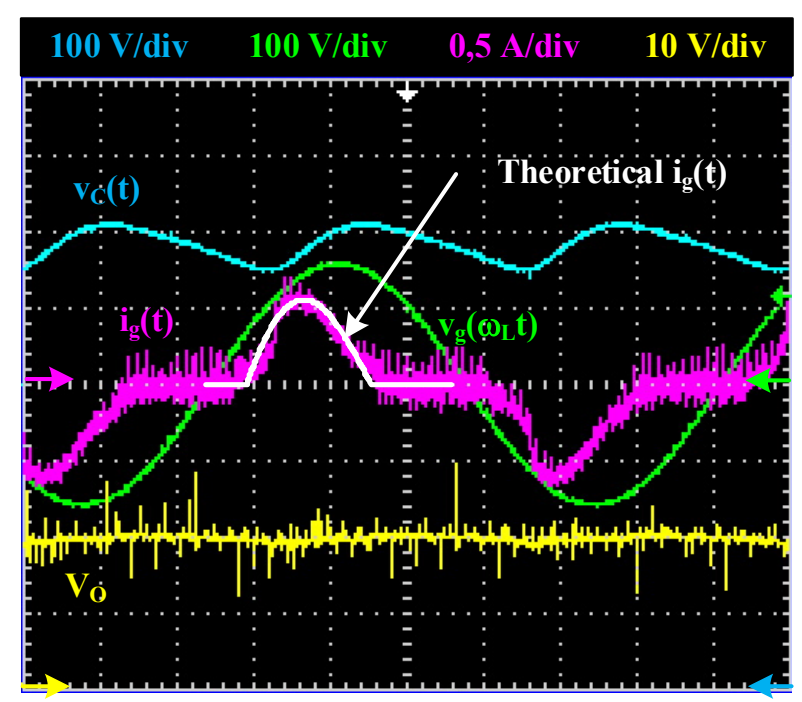

Fig. 8. Line input current $\left(\mathrm{i}_{\mathrm{g}}(\mathrm{t})\right)$, voltage of the intermediate bus $\left(\mathrm{v}_{\mathrm{C}}(\mathrm{t})\right)$, line input voltage $\left(\mathrm{v}_{\mathrm{g}}(\mathrm{t})\right)$ and output voltage $\left(\mathrm{V}_{\mathrm{O}}\right)$ of the AISC with low frequency ripple in the intermediate bus.

Now the question is how the low frequency ripple of the intermediate bus is reflected at the output of the AICS. The answer is shown in Fig. 10. As you can see, the low frequency ripple of the output voltage $\left(\mathrm{V}_{\mathrm{O}}\right)$ and output current $\left(\mathrm{I}_{\mathrm{O}}\right)$ is very low, because the action of the output voltage feedback loop (Fig. $6 \mathrm{~b})$, which have been designed to eliminate this ripple.
In order to validate the absence of flickering, [18] considerations have been followed. To limit the biological effects and detection of flicker in general illumination, the Modulation (\%) should be kept within the shaded region defined by [18]. Modulation (\%) must be calculated by assuming perfect ac power line conditions, being:

$$
\text { Modulation }(\%)_{C}=100 \cdot \frac{\left(L_{\max }-L_{\min }\right)}{\left(L_{\max }+L_{\min }\right)},
$$

where $\mathrm{L}_{\max }$ and $\mathrm{L}_{\min }$ correspond to the maximum and minimum luminance of each harmonic of the ac component of the output current, respectively. In this test a proportionality between luminance and ac component of output current can been assumed. Results of this analysis are shown in Fig. 11. As you can see, all ac harmonic content is within the shaded region.

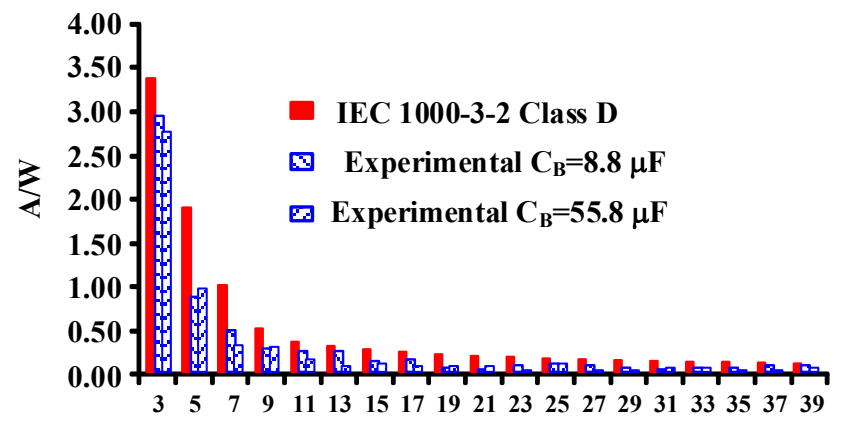

Harmonic

Fig. 9. Experimental harmonic content with and without electrolytic capacitor.

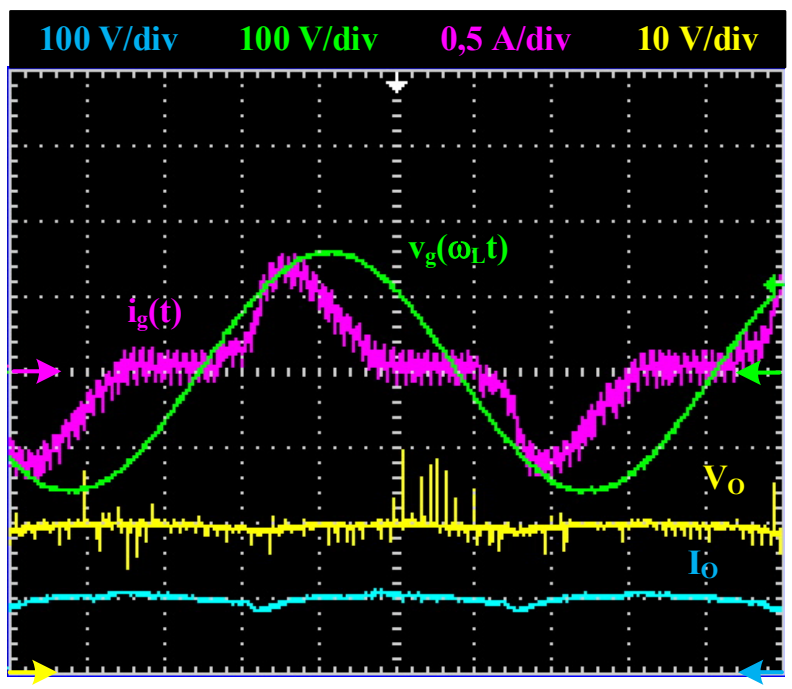

Fig. 10. Line input current $\left(\mathrm{i}_{\mathrm{g}}(\mathrm{t})\right)$, input linevoltage $\left(\mathrm{v}_{\mathrm{g}}(\mathrm{t})\right)$, output voltage $\left(\mathrm{V}_{\mathrm{O}}\right)$ and output current (Io) of the AISC with low frequency ripple in the intermediate bus.

Finally, the efficiency measured in both prototypes are the same, $82 \%$. This efficiency is lower than other proposed topologies for replacing incandescent bulb lamps [7-10]. However, this is the price to pay for eliminating the electrolytic capacitor. 


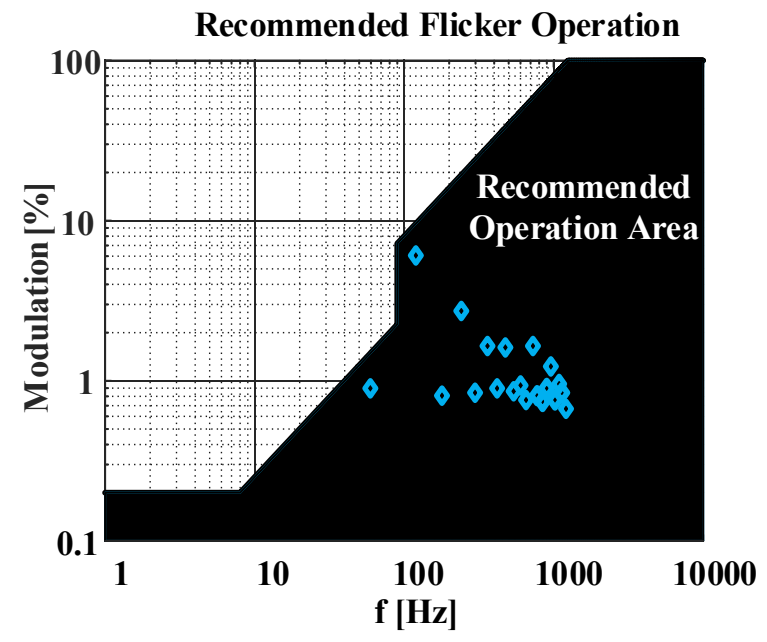

Fig. 11. Modulation (\%) of the ouput current of proposed desing into recommended operation area defined in [18].

TABLE III. PF AND THD OF BOTH TEST

\begin{tabular}{ccc}
\hline TEST & PF & THD(\%) \\
\hline $\begin{array}{c}\text { AISC without low frequency ripple in } \\
\text { the intermediate bus }(\mathrm{CB}=55.8 \mu \mathrm{F})\end{array}$ & 0.871 & 56.2 \\
\hline $\begin{array}{c}\text { AISC with low frequency ripple in the } \\
\text { intermediate bus }(\mathrm{CB}=8.8 \mu \mathrm{F})\end{array}$ & 0.818 & 62.9 \\
\hline
\end{tabular}

\section{ANALYSIS OF THE AISC WITH LOW FREQUENCY VOLTAGE RIPPLE IN THE INTERMEDIATE BUS}

At this point, it is obvious that a theoretical analysis of the AICS solution with low frequency ripple in the intermediate bus must be done. This analysis must be focused on the distortion of the line input current in order to validate the experimental results presented in the second test of the previous section.

If some ripple arises in the intermediate bus of AISC due to the substitution of the electrolytic capacitor by other technology, the constant voltage $\mathrm{V}_{\mathrm{C}}$ becomes $\mathrm{v}_{\mathrm{C}}(\mathrm{t})$ :

$$
v_{C}(t)=V_{C d c}-V_{C a c} \sin \left(2 \omega_{L} t\right)=V_{C d c}\left(1-k \sin \left(2 \omega_{L} t\right)\right) \text {, }
$$

where $\mathrm{V}_{\mathrm{Cdc}}$ and $\mathrm{V}_{\mathrm{Cac}}$ are the dc component and ac component of the voltage across the intermediate bus, and $\mathrm{k}$ is the value of the relative ripple of $\mathrm{vc}_{\mathrm{C}}(\mathrm{t})$. It is important to say that only the component of twice the line frequency of $\mathrm{v}_{\mathrm{C}}(\mathrm{t})$ has been taking into account in the sake of simplicity.

The study will be carried out for a flyback converter operating in CCM (or a member of the flyback's family of de to dc converters, that is, SEPIC, Cuk AND Zeta). Equation (13) and a modification of equation (10) (i.e. changing $d$ by $d(t)$ and $V_{C}$ by $\left.\mathrm{v}_{\mathrm{C}}(\mathrm{t})\right)$, can be used in order to calculate the duty ratio:

$$
d(t)=\frac{V o}{\frac{n_{2}}{n_{1}}\left(V_{C d c}\left(1-k \sin \left(2 \omega_{L} t\right)\right)\right)} .
$$

Now the duty cycle varies with the line frequency due to the action of the output voltage feedback loop, which is designed to keep either the $i_{0}(t)$ or $v_{0}(t)$ constant. This output voltage feedback loop of the vAISC can be designed with very fast dynamic response in order to eliminate the low frequency ripple, which comes from the input of the flyback dc to dc converter (i.e. intermediate bus of the AICS). This characteristic of the AICS [1417] is the key to not transfer the low frequency ripple of $\mathrm{v}_{\mathrm{C}}(\mathrm{t})$ to the output, and to enable that the removal of the electrolytic capacitor does not involve flickering at the output. However, this variation of the duty cycle plus the low frequency ripple of $v_{C}(t)$ has consequences on $\mathrm{V}_{\mathrm{S}}$ (which becomes $\mathrm{v}_{S}(\mathrm{t})$ in this analysis). From a modification of (11) (i.e. changing $d$ by $d(t), V_{C}$ by $v_{C}(t)$ and $V_{S}$ by $v_{S}(t),(13)$ and $(14)$, the expression of $v_{S}(t)$ can be deduced:

$$
v_{S}(t)=V_{o} \frac{\frac{n_{R}}{n_{1}}}{\frac{n_{2}}{n_{1}}} \frac{\left(1-k \sin \left(2 \omega_{L} t\right)\right)}{\left(1-k \sin \left(2 \omega_{L} t\right)\right)+\frac{V_{o}}{\frac{n_{2}}{n_{1}} V_{C d c}}} .
$$

As (15) shows, now $v_{S}(t)$ is not a constant voltage source, and therefore, the line input current will be not sinusoidal during the conduction of the diodes of the rectifier bridge. Using a modification of (3) (i.e., $\mathrm{V}_{\mathrm{C}}$ being $\mathrm{v}_{\mathrm{C}}(\mathrm{t})$ and $\mathrm{V}_{\mathrm{S}}$ being $\mathrm{v}_{\mathrm{S}}(\mathrm{t})$ ), (13) and (15), the line input current will be:

$$
\begin{aligned}
& i_{g d c}(t)=\frac{1}{R_{L F}}\left[V_{g p}\left|\sin \left(\omega_{L} t\right)\right|+V_{o} \frac{\frac{n_{R}}{n_{1}}}{\frac{n_{2}}{n_{1}}} \frac{\left(1-k \sin \left(2 \omega_{L} t\right)\right)}{\left(1-k \sin \left(2 \omega_{L} t\right)\right)+\frac{V_{o}}{n_{2}} V_{1} C d c}-\right. \\
& \left.V_{C d c}\left(1-k \sin \left(2 \omega_{L} t\right)\right)\right] \text {. }
\end{aligned}
$$

It should be noted that this expression is only valid for the interval where $\mathrm{v}_{\mathrm{g}}(\mathrm{t})$ is greater than $\mathrm{v}_{\mathrm{C}}(\mathrm{t})-\mathrm{v}_{\mathrm{S}}(\mathrm{t})$. This interval can be calculated by equaling to zero (16):

$$
\begin{gathered}
V_{g p}\left|\sin \left(\omega_{L} t_{i}\right)\right|+V_{o} \frac{n_{S}}{n} \frac{\left(1-k \sin \left(2 \omega_{L} t_{i}\right)\right)}{\left(1-k \sin \left(2 \omega_{L} t_{i}\right)\right)+\frac{V_{o}}{n V_{C d c}}}- \\
V_{C d c}\left(1-k \sin \left(2 \omega_{L} t_{i}\right)\right)=0 ; \quad i=1,2, \quad(17)
\end{gathered}
$$

where the conduction angle becomes:

$$
\phi_{C}=2 \pi \frac{t_{2}-t_{1}}{T}
$$

As you can deduct from (16), average input current of the AISC with ripple in the intermediate bus is non-sinusoidal during the interval $\left[\mathrm{t}_{1}, \mathrm{t}_{2}\right]$

Finally, the expression of $\mathrm{R}_{\mathrm{LF}}$ can be deduced from the input power by using (17). In sake of simplicity $\mathrm{R}_{\mathrm{LF}}$ has been considered constant in the theoretical analysis:

$$
\begin{array}{r}
R_{L F}=\frac{1}{P_{g} \cdot \frac{T}{2}} \int_{t_{1}}^{t_{2}} i_{g d c}(t) V_{g p}\left|\sin \left(\omega_{L} t\right)\right| d t= \\
\frac{1}{P_{g} \cdot \frac{T}{2}} \int_{t_{1}}^{t_{2}}\left[V_{g p}\left|\sin \left(\omega_{L} t\right)\right|+V_{o} \frac{n_{S}}{n} \frac{\left(1-k \sin \left(2 \omega_{L} t\right)\right)}{\left(1-k \sin \left(2 \omega_{L} t\right)\right)+\frac{V_{o}}{n V_{C d c}}}-\right. \\
\left.V_{C d c}\left(1-k \sin \left(2 \omega_{L} t\right)\right)\right] \cdot V_{g p}\left|\sin \left(\omega_{L} t\right)\right| d t .
\end{array}
$$

At this point, the line input current of the AICS can be theoretically calculated for a given specifications. Figure 12, shows the normalized input current for the same optimized design presented in Fig. 2, but now introducing some ripple on $\mathrm{v}_{\mathrm{C}}(\mathrm{t})$. From Fig. 12 waveforms analysis, we can conclude that the distortion of the line input current due to the low frequency ripple in the intermediate bus is negligible in comparison to the distortion naturally generated by the AISC operation. 
Finally, with the theoretical model presented in this section the line input current of experimental results test $\mathrm{B}$ (i.e. $\mathrm{k}=0.2$ ) can be calculated. As you can see in Fig. 10, the experimental results match with theoretical ones, validating the proposed model.

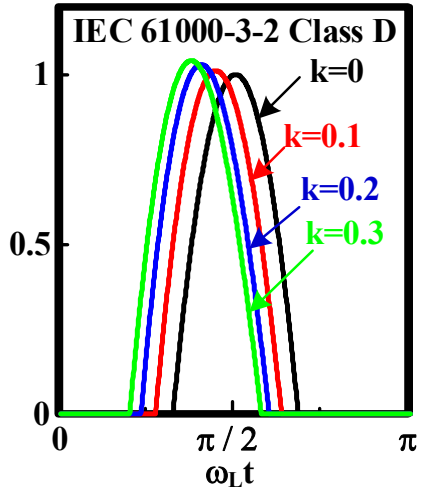

(a)

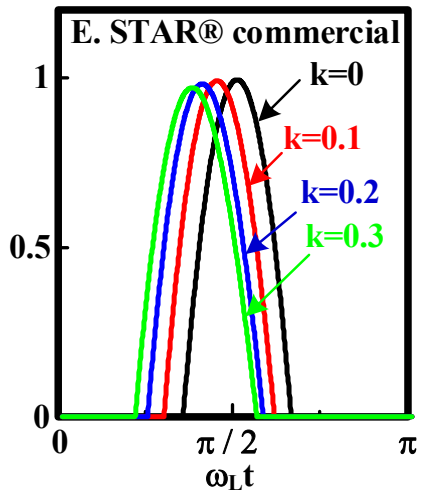

(c)

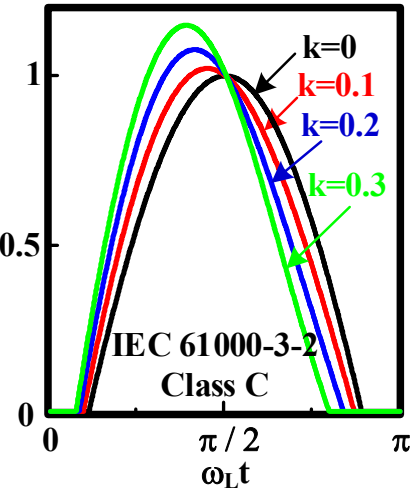

(b)

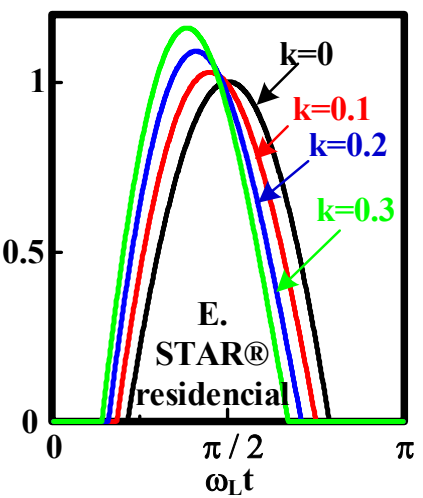

(d)
Fig. 12. Normalized input current for different optimized designs at different peak values of $\mathrm{v}_{\mathrm{g}}(\mathrm{t})$ and $\mathrm{k}$ values: a) Class $\mathrm{D}$ european design. b) Class $\mathrm{C}$ european design. c) ENERGY STAR $®$ american desing for comercial applications. d) ENERGY STAR ${ }^{\circledR}$ american desing for residential applications.

\section{CONCLUSIONS}

This paper presents an ac to dc HB-LED driver with no electrolytic capacitor, based on the AICS solution. By removing the electrolytic capacitor, some low frequency ripple arises in the intermediate bus of the AICS. As a consequence of this, the distortion of the line current is increased. However, as theoretical and experimental results show, this increase in distortion is slight in comparison to the one of a standard AISC, and compliance with international regulations (i.e IEC 61000-32 Class D) is achieved. Moreover, no low frequency ripple is translated to the output due to the fast dynamic response of AICS, and therefore, no flickering performance is obtained in the ac to dc one-stage topology without electrolytic capacitor. However, the proposed solution presents two main drawbacks: slightly lower efficiency in comparison to other solutions and no wide input voltage range performance. This is the price to pay for a very low-cost solution without electrolytic capacitor.

\section{REFERENCES}

[1] Azevedo, I.L.; Morgan, M.G.; Morgan, F, "The Transition to Solid-State Lighting," Proceedings of the IEEE, vol.97, no.3, pp.481-510, March 2009.

[2] Shur, M.S.; Zukauskas, R. "Solid-State Lighting: Toward Superior Illumination," Proceedings of the IEEE, vol.93, no.10, pp.1691-1703, Oct. 2005.

[3] Electromagnetic compatibility (EMC)-part 3: Limits-section 2: Limits for harmonic current emissions (equipment input current $<16 \mathrm{~A}$ per phase), IEC1000-3-2 Document, 1995.

[4] [4] Draft of the proposed CLC Common Modification to IEC 61000-3-2 Document, 2006.

[5] Draft of the proposed CLC Common Modification to IEC 61000-3-2/A2 Document, 2010.

[6] Revised ENERGY STAR Program Requirements for Solid-State Lighting Luminaires: Eligibility Criteria - Version 1.1, December 2008.

[7] Buso, S.; Spiazzi, G.; Sichirollo, F., "Study of the Asymmetrical HalfBridge Flyback Converter as an Effective Line-Fed Solid-State Lamp Driver," Industrial Electronics, IEEE Transactions on , vol.61, no.12, pp.6730,6738, Dec. 2014

[8] X. Qu, S.-C. Wong, and C. K. Tse, "Resonance-assisted buck converter for offline driving of power LED replacement lamps," IEEE Trans. Power Electron., vol. 26, no. 2, pp. 532-540, Feb. 2011.

[9] Lamar, D.G.; Fernandez, M.; Arias, M.; Hernando, M.M.; Sebastian, J., "Tapped-Inductor Buck HB-LED AC-DC Driver Operating in Boundary Conduction Mode for Replacing Incandescent Bulb Lamps," Power Electronics, IEEE Transactions on, vol.27, no.10, pp.4329,4337, Oct. 2012.

[10] Lamar, D.G.; Arias, M.; Hernando, M.M.; Sebastian, J., "Using the LossFree Resistor Concept to Design a Simple AC-DC HB-LED Driver for Retrofit Lamp Applications," Industry Applications, IEEE Transactions on , vol.51, no.3, pp.2300,2311, May-June 2015.

[11] Sebastian, J.; Uceda, J., "Two different types of fully regulated twooutput $\mathrm{dc}^{-}$to- $\mathrm{dc}$ converters with one switch". Second International Conference on Power Electronics and Variable Speed Drives, Birmingham (Reino Unido), noviembre 1986, pp. 172-176.

[12] Sebastian, J.; Uceda, J., "An alternative method for controlling two-output DC-to-DC converters using saturable core inductor," in Power Electronics, IEEE Transactions on , vol.10, no.4, pp.419-426, Jul 1995.

[13] Huber, L.; Jovanovic, M.M., "Single-stage, single-switch, isolated power supply technique with input-current shaping and fast output-voltage regulation for universal input-voltage-range applications," Applied Power Electronics Conference and Exposition, 1997. APEC '97 Conference Proceedings 1997., Twelfth Annual, vol.1, no., pp.272,280 vol.1, 23-27 Feb 1997.

[14] Huber, L.; Jovanovic, M.M., "Design optimization of single-stage singleswitch input-current shapers," Power Electronics, IEEE Transactions on, vol.15, no.1, pp.174,184, Jan 2000.

[15] Sebastian, J.; Hernando, M.M.; Fernandez, A.; Villegas, P.J.; Diaz, J., "Input current shaper based on the series connection of a voltage source and a loss-free resistor," Industry Applications, IEEE Transactions on , vol.37, no.2, pp.583,591, Mar/Apr 2001.

[16] Yimin Jiang; Lee, F.C.; Hua, G.; Tang, W., "A novel single-phase power factor correction scheme," in Applied Power Electronics Conference and Exposition, 1993. APEC '93. Conference Proceedings 1993., Eighth Annual, vol., no., pp.287-292, 7-11 Mar 1993.

[17] Villarejo, J.A.; Sebastian, J.; Soto, F.; de Jodar, E., "Optimizing the Design of Single-Stage Power-Factor Correctors," Industrial Electronics, IEEE Transactions on , vol.54, no.3, pp.1472,1482, June 2007.

[18] IEEE Recommended Practices for Modulating Current in HighBrightness LEDs for Mitigating Health Risks to Viewers," in IEEE Std 1789-2015, vol., no., pp.1-80, June 52015. 